\title{
The impact of timolol maleate on the ocular tolerability of fixed-combination glaucoma therapies
}

This article was published in the following Dove Press journal:

Clinical Ophthalmology

12 December 2014

Number of times this article has been viewed

\author{
Nathan M Radcliffe \\ Ophthalmology, New York University, \\ New York, NY, USA
}

\begin{abstract}
Glaucomatous optic atrophy is the second most common cause of blindness worldwide, and lowering intraocular pressure (IOP) is the only proven method to slow or stop the progression of the disease. Approximately $40 \%$ of patients with elevated IOP will require more than one medication to obtain a modest $20 \%$ reduction in IOP, and as a result, some patients may require two medications, provided in either two separate bottles or in one bottle with the use of fixed-combination therapies. Each therapy has its own unique safety and efficacy profile. Topical beta-blockers have a particularly favorable ocular-tolerability profile, and several studies of fixed-combination medications containing the beta-blocker timolol maleate have shown a lower prevalence of some ocular adverse events for the fixed-combination therapy compared to the non-beta-blocker individual component. In this review, we examined clinical data pertaining to the ocular surface tolerability of fixed-combination medications containing timolol maleate in comparison to the individual components. In particular, preference was given to prospective, randomized, multicenter trials of 3 months in duration or longer that compared a fixed-combination therapy to monotherapy with the individual components. A review of the literature revealed that some fixed-combination therapies can provide a reduced risk of common side effects compared to their individual components, with conjunctival hyperemia and ocular allergy being less frequent in some timolol-containing fixed-combination therapies. This effect appears to be most significant for latanoprost $0.005 \%$, bimatoprost $0.03 \%$, and brimonidine $0.2 \%$.
\end{abstract}

Keywords: bimatoprost, brimonidine, hyperemia, latanoprost, ocular allergy

\section{Introduction}

Glaucomatous optic atrophy is the second most common cause of blindness worldwide and its prevalence increases with certain risk factors, including older age and elevated intraocular pressure (IOP). ${ }^{1,2}$ Lowering IOP is the only proven method to slow or stop the progression of the disease. ${ }^{3,4}$ While incisional and laser-based glaucoma therapies have been shown to effectively treat glaucoma, topical ocular hypotensive therapy is the current mainstay of treatment. ${ }^{5,6}$ Commonly used classes of ocular hypotensive medications include prostaglandin analogs (including prostamides), beta-adrenergic antagonists (beta-blockers), alpha-adrenergic agonists, and carbonic anhydrase inhibitors. ${ }^{7}$ Each of the available molecules from these classes of medications possesses its own unique profile in terms of efficacy, duration of action, dosing requirements, and ocular and systemic tolerability.

Approximately $40 \%$ of patients with elevated IOP will be unable to achieve a modest $20 \%$ reduction in IOP with the use of a single medication. ${ }^{4}$ As a result, patients
Correspondence: Nathan M Radcliffe New York University, 240 E38th St,

New York, NY 10016, USA

Tel +l 2122632573

Fax + I 2122632573

Email drradcliffe@gmail.com 
may require more than one medication, provided in either two separate bottles or in one bottle with the use of fixedcombination therapies.

Single-bottle therapies have inherent advantages over two-bottle therapies. Studies of pharmacy-claims data have demonstrated that patients receiving two IOP-lowering medications with fixed-combination eye drops are more likely to adhere to a year of therapy than those receiving two medications in two separate bottles. ${ }^{8}$ Additionally, taking multiple medications in two separate bottles compared to a fixed-combination typically increases exposure to preservatives, increases the complexity and time commitments of the medical regimen, and can potentially allow the first medication to be "washed out" by the application of the second.

Currently, the majority of available fixed-combination therapies contain a beta-blocker (usually timolol maleate) in addition to another IOP-lowering agent. ${ }^{9}$ While it might be expected that the combination of two medications would result in a safety profile that represents the sum of adverse events experienced with the individual components, several studies of fixed-combination medications containing the beta-blocker timolol maleate have shown a reduction of some ocular adverse events compared to the non-beta-blocker individual component. In this review, we will examine clinical data pertaining to the ocular surface tolerability of fixed-combination medications containing timolol maleate in comparison to the individual components.

\section{Beta-adrenergic antagonists}

Beta-blockers lower IOP by inhibiting aqueous humor production from the nonpigmented ciliary body epithelium through antagonism of $\beta-1$ and $\beta-2$ receptors. The beta-blocker class has been commercially available for the treatment of glaucoma since initial U S Food and Drug Administration (FDA) approval in 1978 and represents one of the most frequently prescribed topical treatments for glaucoma. Advantages of beta-blocker glaucoma therapies include the possibility for daily dosing, including well-established efficacy and a favorable ocular tolerability profile. Several beta-blocker molecules have been developed for ophthalmic use, including timolol maleate, carteolol, levobunolol, metipranolol, and betaxolol. In the Ocular Hypertension Treatment Study, 817 subjects randomized to timolol maleate $0.5 \%$ twice daily experienced a $5.9 \pm 3.4 \mathrm{mmHg}(22 \% \pm 12 \%)$ reduction in IOP. ${ }^{10}$ Beta-blockers are contraindicated or must be used with careful consideration and caution in patients with bradycardia, heart failure, bronchospasm, asthma, and other obstructive pulmonary diseases. Ocular adverse events with timolol are typically mild and include allergy, stinging or burning upon application, and blurred vision. In one 12-month prospective study reported by Sherwood et al 392 patients using timolol maleate $0.5 \%$ twice daily for 12 months were studied carefully for adverse events, and the most common cumulative adverse event (occurring in $>5 \%$ of patients) was conjunctival allergy $(12 \%)$, followed by conjunctival hyperemia (7.4\%) and ocular stinging (6.6\%). ${ }^{11}$ Because of its efficacy and tolerability profile, timolol maleate has maintained an important role in the treatment of glaucoma.

\section{Fixed combinations including timolol and a prostaglandin analog}

The prostaglandin analog class of medications has replaced beta-blockers as the preferred agent for primary glaucoma treatment. ${ }^{12,13}$ Favorable attributes of the prostaglandin analog class include excellent IOP-lowering efficacy, 24-hour IOP control with once-daily dosing, and an acceptable topical side effect profile with very minimal systemic effects. The prostaglandin analog class of medications reduces IOP by increasing aqueous egress through the uveoscleral outflow pathway. ${ }^{14}$ Bimatoprost is classified as a prostamide, is not a prodrug like the prostaglandin analogs, and may function differently than other members of the prostaglandin analog class; however, for the purposes of this review, we consider all agents to be prostaglandin analogs. ${ }^{15}$

In one prospective study comparing the three most widelyused prostaglandin analogs, 410 patients were randomized evenly to three prostaglandin analogs and were followed for 12 weeks. In terms of IOP lowering, treatment produced mean IOP reductions of $6.7 \pm 3.2 \mathrm{mmHg}$ for travoprost, $7.0 \pm 3.2 \mathrm{mmHg}$ for latanoprost $0.005 \%$, and $7.3 \pm 3.1 \mathrm{mmHg}$ for bimatoprost $0.03 \% .{ }^{16}$ Hyperemia rates were $34.8 \%$ for bimatoprost $0.03 \%, 27.3 \%$ for travoprost $0.004 \%$, and $16 \%$ for latanoprost $00.05 \%$. Hyperemia is the most commonly reported adverse event of the prostaglandin analogs and in some studies has occurred in up to $48 \%$ of treated patients, impacting patient persistence with glaucoma therapy. ${ }^{17}$ Because hyperemia may interfere with the use of prostaglandin analogs, efforts have been made to reformulate some prostaglandin analogs in order to improve tolerability. ${ }^{18}$

The combination of timolol with a prostaglandin analog is an appealing fixed-combination therapy for several reasons. Added to a prostaglandin analog, timolol has been considered to be a sensible option and, additionally, has been the most popular adjunctive treatment with a prostaglandin analog. ${ }^{19}$ Both agents may be dosed daily, have well-established efficacy as monotherapy, and have acceptable tolerability 
profiles. Additionally, the two agents utilize complementary mechanisms of action that represent the two most successful approaches to lowering IOP: the reduction of aqueous humor production and the augmentation of aqueous outflow through the uveoscleral pathway. Finally, several long-term prospective studies have demonstrated that, together, their efficacy is additive. ${ }^{20}$

\section{Fixed combination latanoprost $0.005 \%$ and timolol maleate $\mathbf{0 . 5 \%}$}

Higginbotham et al reported on outcomes of the first available fixed combination containing a prostaglandin analog and a beta-blocker: fixed combination latanoprost $0.005 \%$ and timolol maleate $0.5 \%{ }^{21}$ Patients with open-angle glaucoma or ocular hypertension were randomized into three parallel treatment groups receiving the fixed combination or either of the active controls, with daily dosage in the latanoprost $0.005 \%$ and fixed combination arm and twice-daily dosage in the timolol arm. The main outcome measure was IOP reduction at 6 months. After 6 months, all 332 patients in the study were switched to an open-label extension phase using the fixed combination only. Across the three groups, eye irritation was the most commonly reported adverse event and occurred in 15/140 (10.7\%) patients randomized to latanoprost $0.005 \%, 12 / 140(8.6 \%)$ patients randomized to timolol maleate $0.5 \%$, and $19 / 138$ $(13.8 \%)$ patients randomized to the fixed combination. Conjunctival hyperemia occurred in $18(12.9 \%)$ patients on latanoprost $0.005 \%$ therapy, two $(1.4 \%)$ patients on timolol $0.5 \%$, and nine $(6.5 \%)$ patients using the fixed-combination therapy. While the investigators did not report a statistical comparison of the differences in adverse events between groups, by 6 months, twice as many patients developed hyperemia while receiving latanoprost $0.005 \%$ compared to the fixed combination. In summary, the single long-term study to compare latanoprost $0.005 \%$ to its fixed combination containing timolol maleate $0.5 \%$ demonstrated a lower incidence of conjunctival hyperemia using the fixedcombination therapy.

\section{Fixed-combination bimatoprost $0.03 \%$ and timolol $0.5 \%$}

Brandt et al reported outcomes from two identical 3-month prospective double-masked, parallel-design, randomized controlled trials performed at almost 60 study sites. ${ }^{22}$ In a 2:1:1 design, patients were randomized to fixed-combination bimatoprost $0.03 \%$ and timolol $0.5 \%$ dosed once daily in the morning; bimatoprost $0.03 \%$ dosed once daily in the evening; or timolol $0.5 \%$ dosed twice daily. In both studies, 987 patients were evaluated for safety at 3 months. The overall safety profile differed significantly between the three groups, with treatment-related adverse events being reported in $41.5 \%$ of the fixed-combination group, $50.9 \%$ of the bimatoprost $0.03 \%$ monotherapy group, and $24.7 \%$ of the timolol maleate $0.5 \%$ group $(P<0.001)$. Conjunctival hyperemia was the most commonly reported adverse event, occurring in $38.5 \%$ of patients randomized to bimatoprost $0.03 \%, 22.7 \%$ of patients randomized to the fixed combination, and $6.8 \%$ of patients randomized to timolol $0.5 \%$ $(P<0.001)$. Eye pruritus was lowest in the timolol group at $0.8 \%$, followed by the fixed-combination group at $5.1 \%$, and finally the bimatoprost $0.03 \%$ group at $8.7 \%(P<0.001)$. Not all adverse events were lower in the fixed-combination group compared to bimatoprost $0.03 \%$; for example, eyelash growth occurred in $3.6 \%$ and $3.8 \%$ of patients on the fixed combination and bimatoprost $0.03 \%$, respectively, but in only $0.4 \%$ of patients on timolol $0.5 \%(P=0.022)$. Stinging sensation differed significantly between groups $(P=0.046)$ and was most common in the timolol group (3.4\%), followed by the fixed-combination group (2.4\%) and then by the bimatoprost group $(0.4 \%)$.

Lewis et al reported the 12-month outcomes from the Brandt et al study ${ }^{22}$ comparing bimatoprost $0.03 \%$ and timolol $0.5 \%$ to its individual components. ${ }^{23}$ The findings at 3 months were essentially preserved, with conjunctival hyperemia being the most common adverse event occurring in $25.7 \%$ of patients receiving the fixed combination, $43.4 \%$ of patients receiving bimatoprost $0.03 \%$, and $8.7 \%$ of patients receiving timolol $(P<0.001)$. Burning sensation was more common in the timolol $0.5 \%(10.3 \%)$ and fixed-combination $(8.3 \%)$ groups than the bimatoprost $0.03 \%$ arm $(10.3 \% ; P=0.043)$, with a similar finding for stinging sensation. Eyelash growth occurred more frequently and at similar rates, both in arms containing bimatoprost $0.03 \%$, but eyelid pigmentation occurred less frequently in the fixed-combination group $(3.2 \%)$ than in the bimatoprost arm $(9.1 \% ; P<0.001)$. Taken together, these findings suggest that timolol maleate, when given in a fixed combination with bimatoprost $0.03 \%$, can be associated with a lower incidence of some, but perhaps not all, of the ocular adverse events associated with bimatoprost. After 1 year, these differences in tolerability did seem to be clinically significant, as $4.2 \%$ of patients in the study discontinued participation due to conjunctival hyperemia in the bimatoprost $0.03 \%$ group, but only $1.5 \%$ in the fixed-combination group and $1.9 \%$ in the timolol $0.5 \%$ group $(P<0.044)$. 
Konstas et al evaluated 60 patients with exfoliation glaucoma in a prospective, investigator-masked, crossover comparison of bimatoprost $0.03 \%$ and timolol $0.5 \%$ compared to bimatoprost $0.03 \%$ monotherapy. ${ }^{24}$ The investigators found that conjunctival hyperemia occurred in $25 \%$ of patients receiving bimatoprost $0.03 \%$ compared to only $6.7 \%$ of patients receiving the fixed combination $(P=0.03 \%)$. However, stinging was more common, occurring in $25 \%$ of eyes receiving the fixed combination as compared to $10 \%$ of eyes receiving bimatoprost $0.03 \%(P=0.022)$. Katsanos et al performed a small $(\mathrm{n}=33)$ single-armed study in which patients were run in on bimatoprost for 5 weeks and then switched to bimatoprost $0.03 \%$ and timolol $0.5 \%$ fixed combination. ${ }^{25}$ Ocular hyperemia was present in seven patients $(21.2 \%)$ receiving bimatoprost monotherapy and in only two $(6 \%)$ after the switch to the fixed combination $(P=0.06)$. There was a total of 29 adverse ocular events with bimatoprost $0.03 \%$ compared to 19 with the fixed combination $(P=0.09)$.

Paranhos et al sought to evaluate changes in hyperemia and IOP in patients who were switched from prostaglandin analog monotherapy to a fixed combination of bimatoprost $0.03 \%$ and timolol $0.5 \% .{ }^{26}$ In this multicenter longitudinal, noncontrolled, nonrandomized, open-label trial study of 282 eyes of 144 patients, IOP and conjunctival hyperemia were assessed prior to treatment with the fixed combination and 4 months after the medication was switched. Four months after a switch to the beta-blocker containing fixed combination, hyperemia was reduced in patients who had previously used travoprost $0.004 \%$, latanoprost $0.005 \%$, or bimatoprost $0.03 \%$. Graded on a scale from 0 to 3 , hyperemia was reduced more than $50 \%$ after switching from the bimatoprost $0.03 \%$ and travoprost $0.004 \%$ monotherapy groups, and less so in the latanoprost $0.005 \%$ group, which also had a lower level of baseline hyperemia. All groups experienced significant IOP reduction with the fixed-combination therapy.

In summary, there is strong evidence from several large prospective longitudinal trials that hyperemia seen with bimatoprost $0.03 \%$ is reduced when that agent is taken in a fixed-combination therapy with timolol maleate $0.5 \%$.

\section{Fixed-combination travoprost and timolol}

Barnebey et al reported the results of a 3-month prospective, randomized, multicenter, double-masked, active-controlled, parallel-group study comparing travoprost $0.004 \%$ alone to a fixed combination of travoprost $0.004 \% /$ timolol maleate $0.5 \%$ in patients with ocular hypertension or openangle glaucoma. ${ }^{27}$ All therapies in this study contained benzalkonium chloride as the preservative. Ocular hyperemia was assessed at all IOP time points ( $8 \mathrm{am}, 10 \mathrm{am}$, and $4 \mathrm{pm}$ ) and a slit-lamp examination was performed at 8 am at each visit. The primary outcome of the study was mean IOP; however, each of the 263 patients enrolled in the study was evaluated for safety. Patient-reported ocular hyperemia occurred in $14 \%$ of patients receiving the fixed combination and in $12 \%$ of patients receiving travoprost $0.004 \%$. Seven percent of patients receiving timolol $0.5 \%$ reported ocular discomfort, and only one patient, or $1.1 \%$, in the timolol group reported hyperemia. No additional systemic or topical safety concerns were reported. Therefore, in this 3-month study, there was no observed difference in ocular tolerability between the fixed combination and travoprost $0.004 \%$. Although the study carefully assessed ocular adverse events, it is possible that the relatively short-term (3-month) study duration did not allow enough time for ocular allergy to develop or for any differences to be observed between groups. Because the study was powered for a primary endpoint of IOP reduction, it is possible that the study was underpowered to find a small benefit in terms of tolerability, although the study was likely large enough to detect any clinically relevant tolerability differences. It is also possible that hyperemia associated with travoprost is of a different nature then hyperemia seen with latanoprost and bimatoprost.

\section{Summary of fixed-combination prostaglandin analogs and timolol maleate}

Quaranta et al performed a meta-analysis of 18 prospective randomized trials comparing fixed combinations of prostaglandin analogs and timolol to prostaglandin monotherapy or to the two medications taken as an unfixed combination in separate bottles..$^{28}$ Compared to monotherapy with a prostaglandin analog, the fixed-combination therapies were associated with significantly lower hyperemia risk ratio (RR) of 0.61 (95\% confidence interval [CI]: 0.53-0.70). Consistent with findings reviewed above, the amount of hyperemia reduction in the fixed combination depended on the prostaglandin molecule received prior to the switch. Bimatoprost $0.03 \%$ demonstrated the largest magnitude of hyperemia reduction (RR: 0.59, 95\% CI: $0.51-0.68$ ) followed by latanoprost $0.005 \%$ (RR: $0.65,95 \%$ CI: $0.42-0.99$ ). The reduction in hyperemia from travoprost was not statistically significant (RR: 0.94, 95\% CI: 0.50-1.77); however, there were the fewest studies in the travoprost group and the CIs for that group were the widest, demonstrating that there is some uncertainty regarding the magnitude and direction of the effect. 
The above findings support that hyperemia reduction occurs from the addition of timolol maleate in fixed combination with a prostaglandin analog, particularly if that prostaglandin analog is bimatoprost $0.03 \%$ or latanoprost $0.005 \%$. The mechanism of how a beta-blocker might alleviate prostaglandin-induced hyperemia is unknown. Several hypotheses exist, but the exact cause of prostaglandin-mediated hyperemia is also incompletely understood. Hyperemia associated with prostaglandin analog use is not considered to be inflammatory in nature, as inflammation was not observed on histological evaluation of conjunctival biopsies. ${ }^{29}$ It has been suggested that intracellular calcium and endothelium-derived nitric oxide cause conjunctival vasodilation and hyperemia from prostaglandin analogs. ${ }^{30}$ Beta-blockers may inhibit nitric oxide production induced by endogenous catecholamines that are involved with conjunctival hyperemia.

\section{Ocular tolerability of carbonic anhydrase inhibitors in combination with timolol maleate}

The carbonic anhydrase inhibitor class has been used in humans for glaucoma treatment since 1954 when Becker reported its efficacy for the reduction of IOP as an oral agent. ${ }^{31}$ Of the fixed combinations currently available in the United States, dorzolamide hydrochloride $2 \%$ and timolol maleate $0.5 \%$ fixed combination has been available the longest, having achieved FDA approval in 1998. ${ }^{32}$ Today, two topical carbonic anhydrase inhibitors, dorzolamide and brinzolamide, have been formulated for glaucoma therapy and are available in fixed combination with timolol maleate; however, only dorzolamide timolol fixed combination is FDA-approved and has been studied in comparison with its individual components. In a prospective, randomized study evaluating differences in ocular discomfort between two fixed combinations containing the preservative benzalkonium chloride, the fixed combination containing dorzolamide and timolol was associated with greater ocular discomfort than the fixed combination of brinzolamide and timolol. ${ }^{33}$

Boyle performed a 3-month, parallel-design, randomized, double-masked, active-controlled, multicenter clinical trial, randomizing 335 patients to timolol maleate $0.5 \%$, dorzolamide $2 \%$, or the fixed combination. ${ }^{34}$ The study demonstrated an IOP-lowering benefit of the fixed combination compared to the individual components. Discontinuations due to adverse events occurred in $7 \%$ of patients using the fixed combination and in $1 \%$ of patients using timolol maleate $0.5 \%$. The most commonly reported adverse events included blurred vision, burning, stinging, and tearing, and occurred in more patients using the fixed combination compared to timolol. Hyperemia occurred in $1 \%$ of patients using timolol $0.5 \%$, in $4 \%$ using dorzolamide, and in $3 \%$ of patients using the fixed combination.

Clineschmidt et al performed a similar prospective, randomized, clinical trial comparing timolol maleate $0.5 \%$, dorzolamide $2 \%$, and the fixed combination. ${ }^{35}$ The study included 253 patients and evaluated efficacy and tolerability at 3 months. As with the Boyle study, patients randomized to timolol had fewer adverse events than those using either dorzolamide $2 \%$ or the fixed combination, which had similar safety profiles. Burning and stinging were the most common local adverse events and occurred in $45 \%$ of patients using the combination, $45 \%$ of patients using dorzolamide, and $27 \%$ of those using timolol. Dorzolamide-containing fixed combinations may provide nighttime IOP control. In a prospective, randomized 3-month study comparing 24-hour IOP reduction in patients receiving either dorzolamide-timolol or brimonidine-timolol, dorzolamide-timolol reduced 24-hour IOP by $0.7 \mathrm{mmHg}$ more than brimonidine-timolol ( $P=0.001)$, although both medications significantly reduced IOP $(P=0.001) .{ }^{36}$ The mechanism for this difference has not been elucidated, and the relative importance of nighttime IOP control remains unclear, as all prospective National Institute of Health-sponsored studies have only included daytime IOP.

In summary, the addition of timolol to dorzolamide in a fixed combination did not appear to significantly reduce the ocular tolerability in comparison to dorzolamide alone, although timolol was better tolerated than either dorzolamide or the fixed combination in both studies. While both studies contained several hundred patients and evaluated the individual components in comparison to the combination, the studies were only 3 months in duration, so it is possible, though perhaps unlikely, that an effect could have emerged if given more time. Additionally, it is notable that stinging and burning, not hyperemia, were the most common side effects with both dorzolamide and the fixed combination. Because timolol itself is associated with stinging, and because dorzolamide causes stinging but has a low rate of hyperemia, the addition of timolol was unable to benefit the tolerability profile of fixedcombination dorzolamide $2 \%$ and timolol maleate $0.5 \%$.

\section{Ocular tolerability of alpha- adrenergic agonists in combination with beta-blockers}

The alpha-adrenergic class has been used as an ocular hypotensive agent since apraclonidine was first FDA-approved 
for topical ophthalmic use in 1989. Apraclonidine is a para-amino derivative of clonidine with relative alphaadrenergic selectivity and was initially used to blunt argon laser trabeculoplasty-related IOP elevations. ${ }^{37}$ However, the $1 \%$ concentration of apraclonidine, formulated for chronic glaucoma treatment, was found to have a $48 \%$ incidence of severe follicular conjunctivitis resulting in discontinuation after a mean duration of 13.3 months. ${ }^{38}$

Brimonidine is an alpha-agonist initially introduced in a $0.5 \%$ concentration for prophylaxis of IOP elevations following laser trabeculectomy. Brimonidine $0.5 \%$ can reduce IOP significantly in the short-term. For example, with brimonidine $0.5 \%$, the incidence of IOP elevation $>5 \mathrm{mmHg}$ after argon laser trabeculoplasty was $38 \%$ whereas with brimonidine $0.5 \%$, these pressure elevations occurred in only $3 \%-9 \%$ of cases..$^{39}$ Brimonidine has subsequently been reformulated into $0.2 \%, 0.15 \%$, and $0.1 \%$ concentrations with accompanying changes in $\mathrm{pH}$, preservative, viscosity, and electrolyte formulation. In the $0.2 \%$ concentration taken three times daily, brimonidine has been shown to reduce IOP by roughly $20 \%$ from baseline and has a 12-month allergic conjunctivitis rate of $9.4 \% .{ }^{11}$ Researchers have demonstrated that brimonidine likely utilizes both the aqueous suppression as well as uveoscleral outflow pathways. ${ }^{40,41}$ Because of its complementary mechanisms of action, potential for twice-daily dosing in a fixed combination, and favorable efficacy and safety profile, a brimonidine $0.2 \%$ and timolol $0.5 \%$ fixed combination was developed by Allergan, Inc. (Irvine, CA, USA), receiving approval by the FDA in 2007.

Sherwood et al reported 12-month outcomes on the safety and efficacy of twice-daily brimonidine $0.2 \%$ and timolol $0.5 \%$ fixed combination compared to monotherapy with either twice-daily timolol $0.5 \%$ or three-times-daily brimonidine $0.2 \%$ in two identical randomized double-masked multicenter trials. ${ }^{11}$ In this investigation, patients receiving the fixed combination had a lower incidence of treatmentrelated adverse events. Adverse events occurred in $62.8 \%$ of the brimonidine $0.2 \%$ monotherapy group compared to $53.0 \%$ in the fixed-combination group $(P=0.006)$ with similar differences in discontinuations due to adverse events $(30.6 \%$ with brimonidine monotherapy and $14.3 \%$ with the fixed combination, $P<0.001)$. Those adverse events related to allergic conjunctivitis occurred in $39.8 \%$ of patients receiving brimonidine compared to $26.0 \%$ of patients receiving the fixed combination $(P<0.001)$. Conjunctival hyperemia was lowest with timolol $(7.4 \%)$, followed by the fixed combination (14.8\%), and was highest with brimonidine $(22.8 \%$; $P=0.001-0.003)$. As has been seen in previous studies, both timolol and the fixed combination had a higher rate of stinging
(6.6\% and $6.2 \%$, respectively) than brimonidine $(2.9 \%$, $P=0.03$ compared to the fixed combinations). ${ }^{22-24,34,35}$ Note that brimonidine was dosed three times daily, consistent with its FDA approval and a necessary design feature in order to meet regulatory requirements, which may account for the higher occurrence of adverse outcomes in the brimonidine arm.

Motolko performed a comparative, nonrandomized, single-site, interventional study in which patients receiving fixed combination of brimonidine $0.2 \%$ and timolol $0.5 \%$ were compared to those receiving brimonidine $0.2 \%$ twice daily as monotherapy. ${ }^{42}$ Ocular allergy in the 204 patients evaluated in this study was defined as the presence of conjunctival follicles significant enough to result in discontinuation of the medication. Over 18 months, allergic conjunctivitis occurred in $17.6 \%$ of the brimonidine twice-daily group and $8.8 \%$ of the fixed-combination group $(P=0.09)$. While the finding was not statistically significant, the incidence of ocular allergy was 50\% lower in the fixed-combination group. The Kaplan-Meier survival analysis evaluating whether ocular allergy may be delayed or reduced in the fixed-combination brimonidine timolol group suggested a statistical trend for a protective effect from the fixed combination $(P=0.066)$. Therefore, in this investigation of twice-daily brimonidine $0.2 \%$ compared to the fixed combination of timolol and brimonidine, the fixed combination demonstrated similar tolerability advantages as seen when the fixed combination was compared to three-times-daily brimonidine.

Osborne et al investigated brimonidine allergy by evaluating a database of 463 patients treated for elevated IOP with pharmacotherapy. ${ }^{43}$ The authors noted that allergy to timolol presented more quickly in patients who had previously demonstrated an allergy to brimonidine, but that those who used timolol initially had a longer period of time until the development of brimonidine allergy $(P=0.037)$. The authors concluded that brimonidine allergy can induce allergy to timolol, but that prior use of timolol might suppress the subsequent development of brimonidine allergy.

Butler et al hypothesized that adrenergic agents may induce allergic response by reducing conjunctival cell volume, which would induce a widening of intercellular spaces, increasing the likelihood that allergens could reach subepithelial tissue. ${ }^{38}$ Evidence in support of this theory comes from a study by Alvarado et al in cultured human trabecular meshwork and Schlemm's canal endothelial cells, which demonstrated decreased cell volume after exposure to adrenergic agonists. ${ }^{44}$ Theoretically, a beta-adrenergic antagonist could inhibit the decrease in cell volume caused by an alpha-adrenergic agent, which would inhibit allergen 
exposure and subsequent allergy development. In summary, there is good evidence from several prospective studies that brimonidine ocular surface tolerability is improved by the presence of timolol in fixed-combination therapy, and that this benefit applies to both hyperemia and the characteristic brimonidine allergy.

\section{Discussion}

Timolol maleate appears to provide benefits to the ocular surface in fixed combinations containing some prostaglandin analogs and alpha-agonists (Table 1). Beta-blockers seem to limit hyperemia, possibly by interfering with pharmacologic mediators of hyperemia, and may decrease allergy by inhibiting intracellular volume reduction. However, some important questions remain. If timolol is protective against ocular surface adverse events, is it necessary for the timolol to be contained in a fixed combination, or can the protection be achieved with concomitant therapy in a separate bottle? While Osborne et al's study ${ }^{43}$ suggested that protection against brimonidine allergy could be achieved by timolol use in a separate bottle, other data suggest that the benefit may be greatest when timolol is contained within a fixed combination. Schuman et al performed a prospective, randomized, double-masked, parallel-group, multicenter trial comparing travoprost $0.004 \% /$ timolol $0.5 \%$ to concomitant timolol $0.5 \%$ and travoprost $0.004 \%$ daily or to timolol $0.5 \%$ twice daily and found that tolerability can differ between concomitant therapy and fixed-combination therapy. ${ }^{45}$ Conjunctival hyperemia occurred in $14.3 \%$ of patients receiving the fixed combination (taken in the morning) compared to $23.4 \%$ of subjects receiving concomitant therapy (with the prostaglandin analog dosed in the evening and timolol dosed in the morning). This study suggests that the benefits of timolol on ocular tolerability may be greater when the timolol is in the same bottle as the prostaglandin analog, although an alternative explanation is that the two agents were also dosed at the same time in the fixed combination whereas concomitant therapy was dosed at opposite times of the day. In a similar large study comparing fixed-combination timolol $0.5 \%$ and travoprost $0.004 \%$ to travoprost $0.004 \%$ and timolol $0.5 \%$ taken in separate bottles and dosed at the same time of day, the ocular tolerability of fixed-combination travoprost $0.004 \%$ /timolol $0.5 \%$ was similar to concomitant therapy, with hyperemia occurring in $12.4 \%$ of those receiving the fixed-combination and $13.5 \%$ of those receiving concomitant therapy. ${ }^{46}$

Hommer et al randomized 445 patients to therapy with fixed-combination bimatoprost $0.03 \%$ /timolol $0.5 \%$ taken daily; concomitant therapy with daily bimatoprost $0.03 \%$ and twice-daily timolol $0.5 \%$; or daily bimatoprost $0.03 \%$ (which was a smaller portion of the study patients). ${ }^{47}$ Interestingly, the cumulative prevalence of conjunctival hyperemia was slightly lower (but not statistically so; $P=0.218$ ) in the fixed-combination group (19.3\%) compared with the nonconcomitant-therapy group (25.6\%) and the bimatoprost monotherapy group (27.8\%). Based on conjunctival hyperemia graded during slit-lamp examination, the incidence of hyperemia increase by one or more grades was higher in the bimatoprost group (18.9\%) than in the fixed-combination group $(8.5 \%, P=0.014)$, with the concomitant-therapy group falling in between the two at $12.5 \%$ (not statistically significant). The incidence of ocular burning was higher in the concomitant-therapy group $(14.2 \%)$ than in the fixedcombination $(6.8 \%, P=0.024)$ and bimatoprost groups $(5.6 \%, P=0.035)$. In summary, there is some conflicting data demonstrating the benefits of timolol on the ocular surface in patients receiving concomitant therapy, though several investigations suggest that timolol's greatest benefit may be achieved when in a fixed combination rather than when taken as concomitant therapy.

\section{Conclusion}

Fixed-combination therapies offer several advantages to patients with glaucoma, including convenience, reduced exposure to preservatives, reduced risk of medication

Table I Hyperemia differences between timolol maleate, non-beta-blocker components, and the fixed combination in prospective, randomized trials

\begin{tabular}{|c|c|c|c|c|c|c|c|}
\hline \multirow[t]{2}{*}{ Authors } & \multirow[t]{2}{*}{ Component } & \multirow[t]{2}{*}{$\mathbf{N}$} & \multirow[t]{2}{*}{ Duration (months) } & \multicolumn{3}{|c|}{ Hyperemia incidence } & \multirow[t]{2}{*}{$P$} \\
\hline & & & & Timolol & Component & Fixed combination & \\
\hline Higginbotham et al' ${ }^{21}$ & Latanoprost $0.005 \%$ & 332 & 6 & $1.4 \%$ & $12.9 \%$ & $6.5 \%$ & ns \\
\hline Brandt et $\mathrm{a}^{22}$ & Bimatoprost $0.03 \%$ & 987 & 3 & $6.8 \%$ & $38.5 \%$ & $22.7 \%$ & $<0.001$ \\
\hline Lewis et $\mathrm{a}^{23}$ & Bimatoprost $0.03 \%$ & $|, 06|$ & 12 & $8.7 \%$ & $43.4 \%$ & $25.7 \%$ & $<0.001$ \\
\hline Barnebey et $\mathrm{a}^{27}$ & Travoprost $0.004 \%$ & 263 & 3 & $1.1 \%$ & $14.1 \%$ & $11.6 \%$ & ns \\
\hline Sherwood et al" & Brimonidine & 392 & 12 & $0.3 \%$ & $22.8 \%$ & $7.4 \%$ & 0.001 \\
\hline Boyle et $\mathrm{a}^{3^{34}}$ & Dorzolamide & 335 & 3 & $1 \%$ & $4 \%$ & $3 \%$ & ns \\
\hline
\end{tabular}

Abbreviation: ns, nonsignificant. 
washout, ease of compliance, and decreased time requirements for eye drop application. ${ }^{8}$ All FDA-approved fixed-combinations have demonstrated added efficacy in comparison to the individual components. However, some fixed-combination therapies can also provide a reduced risk of common side effects compared to their individual components. ${ }^{11,21,22}$ Conjunctival hyperemia and allergy are two of the most common eye drop side effects and are common causes of medication discontinuation. ${ }^{17}$ In this review, we have presented evidence that some fixed-combination therapies that contain timolol maleate have more favorable ocular surface tolerability than the non-timolol individual component. This effect appears to be most significant for latanoprost $0.005 \%$, bimatoprost $0.03 \%$, and brimonidine $0.2 \%$. The effect appears not to be present for dorzolamide, possibly because both timolol and dorzolamide are associated with some stinging, and because dorzolamide and timolol both have lower rates of allergy and hyperemia.

\section{Acknowledgments}

This work was supported by Allergan, Inc., the Seth Sprague Educational \& Charitable Foundation, and Research to Prevent Blindness.

\section{Disclosures}

The author reports the following financial relationships: Reichert (instrument support), Allergan, Inc. (consultant and speaker), Alcon Laboratories (consultant and speaker), Iridex (consultant and speaker), Glaucos (consultant and speaker), Merge Healthcare (consultant and speaker), Carl Zeiss Meditec (consultant and speaker). The author reports no other conflicts of interest in this work.

\section{References}

1. Quigley HA. Number of people with glaucoma worldwide. Br J Ophthalmol. 1996;80(5):389-393.

2. Tielsch JM, Sommer A, Katz J, Royall RM, Quigley HA, Javitt J. Racial variations in the prevalence of primary open-angle glaucoma: the Baltimore Eye Survey. JAMA. 1991;266(3):369-374.

3. Heijl A, Leske MC, Bengtsson B, et al. Reduction of intraocular pressure and glaucoma progression: results from the Early Manifest Glaucoma Trial. Arch Ophthalmol. 2002;120(10):1268-1279.

4. Kass MA, Heuer DK, Higginbotham EJ, et al. The Ocular Hypertension Treatment Study: a randomized trial determines that topical ocular hypotensive medication delays or prevents the onset of primary openangle glaucoma. Arch Ophthalmol. 2002;120(6):701-713.

5. Ederer F, Gaasterland DA, Dally LG, et al. The Advanced Glaucoma Intervention Study (AGIS): 13. Comparison of treatment outcomes within race: 10-year results. Ophthalmology. 2004;111(4):651-664.

6. Lee DA, Higginbotham EJ. Glaucoma and its treatment: a review. Am J Health Syst Pharm. 2005;62(7):691-699.

7. Toris CB. Pharmacotherapies for glaucoma. Curr Mol Med. 2010;10(9): 824-840.
8. Higginbotham EJ, Hansen J, Davis EJ, Walt JG, Guckian A. Glaucoma medication persistence with a fixed combination versus multiple bottles. Curr Med Res Opin. 2009;25:2543-2547.

9. Fechtner RD, Realini T. Fixed combinations of topical glaucoma medications. Curr Opin Ophthalmol. 2004;15(2):132-135.

10. Piltz J, Gross R, Shin DH, et al. Contralateral effect of topical betaadrenergic antagonists in initial one-eyed trials in the ocular hypertension treatment study. Am J Ophthalmol. 2000;130(4):441-453.

11. Sherwood MB, Craven ER, Chou C, et al. Twice-daily $0.2 \%$ brimonidine- $0.5 \%$ timolol fixed-combination therapy vs monotherapy with timolol or brimonidine in patients with glaucoma or ocular hypertension: a 12-month randomized trial. Arch Ophthalmol. 2006;124(9): $1230-1238$.

12. Stewart WC, Stewart JA, Nelson LA, Kruft B. Physician attitudes regarding prostaglandin treatment for glaucoma in the United States and Europe. Eur J Ophthalmol. 2008;18:199-204.

13. Stewart WC, Konstas AG, Pfeiffer N. Patient and ophthalmologist attitudes concerning compliance and dosing in glaucoma treatment. J Ocul Pharmacol Ther. 2004;20:461-469.

14. Toris CB, Gabelt BT, Kaufman PL. Update on the mechanism of action of topical prostaglandins for intraocular pressure reduction. Surv Ophthalmol. 2008;53(Supp1 1):S107-S120.

15. Liang Y, Woodward DF, Guzman VM, et al. Identification and pharmacological characterization of the prostaglandin FP receptor and FP receptor variant complexes. Br J Pharmacol. 2008;154:1079-1093.

16. Parrish RK, Palmberg P, Sheu WP; XLT Study Group. A comparison of latanoprost, bimatoprost, and travoprost in patients with elevated intraocular pressure: a 12-week, randomized, masked-evaluator multicenter study. Am J Ophthalmol. 2003;135(5):688-703.

17. Zimmerman TJ, Hahn SR, Gelb L, Tan H, Kim EE. The impact of ocular adverse effects in patients treated with topical prostaglandin analogs: changes in prescription patterns and patient persistence. $J$ Ocul Pharmacol Ther. 2009;25(2):145-152.

18. Katz LJ, Cohen JS, Batoosingh AL, Felix C, Shu V, Schiffman RM. Twelve-month, randomized, controlled trial of bimatoprost $0.01 \%$, $0.0125 \%$, and $0.03 \%$ in patients with glaucoma or ocular hypertension. Am J Ophthalmol. 2010;149(4):661-671.e1.

19. Cheng JW, Li Y, Wei RL. Systematic review of intraocular pressurelowering effects of adjunctive medications added to latanoprost. Ophthalmic Res. 2009;42(2):99-105.

20. Aptel F, Denis P. Balancing efficacy and tolerability of prostaglandin analogues and prostaglandin-timolol fixed combinations in primary open-angle glaucoma. Curr Med Res Opin. 2011;27(10):1949-1958.

21. Higginbotham EJ, Feldman R, Stiles M, Dubiner H; Fixed Combination Investigative Group. Latanoprost and timolol combination therapy vs monotherapy: one-year randomized trial. Arch Ophthalmol. 2002;120(7):915-922.

22. Brandt JD, Cantor LB, Katz LJ, et al. Bimatoprost/timolol fixed combination: a 3-month double-masked, randomized parallel comparison to its individual components in patients with glaucoma or ocular hypertension. J Glaucoma. 2008;17:211-216.

23. Lewis RA, Gross RL, Sall KN, et al. The safety and efficacy of bimatoprost/timolol fixed combination: a 1-year double-masked, randomized parallel comparison to its individual components in patients with glaucoma or ocular hypertension. J Glaucoma. 2010;19(6):424-426.

24. Konstas AG, Holló G, Mikropoulos D, et al. Twenty-four-hour intraocular pressure control with bimatoprost and the bimatoprost/timolol fixed combination administered in the morning, or evening in exfoliative glaucoma. Br J Ophthalmol. 2010;94(2):209-213.

25. Katsanos A, Dastiridou AI, Fanariotis M, Kotoula M, Tsironi EE. Bimatoprost and bimatoprost/timolol fixed combination in patients with open-angle glaucoma and ocular hypertension. J Ocul Pharmacol Ther. 2011;27(1):67-71.

26. Paranhos A, Mendonça M, Silva MJ, et al. Hyperemia reduction after administration of a fixed combination of bimatoprost and timolol maleate to patients on prostaglandin or prostamide monotherapy. J Ocul Pharmacol Ther. 2010;26:611-615. 
27. Barnebey HS, Orengo-Nania S, Flowers BE, et al. The safety and efficacy of travoprost $0.004 \% /$ timolol $0.5 \%$ fixed combination ophthalmic solution. Am J Ophthalmol. 2005;140(1):1-7.

28. Quaranta L, Biagioli E, Riva I, et al. Prostaglandin analogs and timololfixed versus unfixed combinations or monotherapy for open-angle glaucoma: a systematic review and meta-analysis. J Ocul Pharmacol Ther. 2013;29:382-389.

29. Leal BC, Medeiros FA, Medeiros FW, Santo RM, Susanna R Jr. Conjunctival hyperemia associated with bimatoprost use: a histopathologic study. Am J Ophthalmol. 2004;138(2):310-313.

30. Chen J, Dinh T, Woodward DF, et al. Bimatoprost: mechanism of ocular surface hyperemia associated with topical therapy. Cardiovasc Drug Rev. 2005;23(3):231-246.

31. Becker B. Decrease in intraocular pressure in man by a carbonic anhydrase inhibitor, diamox; a preliminary report. Am J Ophthalmol. 1954; 37(1):13-15.

32. Sugrue MF. Pharmacological and ocular hypotensive properties of topical carbonic anhydrase inhibitors. Prog Retin Eye Res. 2000;19(1): 87-112.

33. Nebbioso M, Evangelista M, Librando A, Di Blasio D, Pescosolido N. Fixed topical combinations in glaucomatous patients and ocular discomfort. Expert Opin Pharmacother. 2012;13:1829-1835.

34. Boyle JE, Ghosh K, Gieser DK, Adamsons IA. A randomized trial comparing the dorzolamide-timolol combination given twice daily to monotherapy with timolol and dorzolamide. Dorzolamide-Timolol Study Group. Ophthalmology. 1998;105(10):1945-1951.

35. Clineschmidt CM, Williams RD, Snyder E, Adamsons IA. A randomized trial in patients inadequately controlled with timolol alone comparing the dorzolamide-timolol combination to monotherapy with timolol or dorzolamide. Dorzolamide-Timolol Combination Study Group. Ophthalmology. 1998;105(10):1952-1959.

36. Konstas AG, Quaranta L, Yan DB, et al. Twenty-four hour efficacy with the dorzolamide/timolol-fixed combination compared with the brimonidine/timolol-fixed combination in primary open-angle glaucoma. Eye (Lond). 2012;26:80-87.

37. Robin AL. The role of apraclonidine hydrochloride in laser therapy for glaucoma. Trans Am Ophthalmol Soc. 1989;87:729-761.
38. Butler P, Mannschreck M, Lin S, Hwang I, Alvarado J. Clinical experience with the long-term use of $1 \%$ apraclonidine: Incidence of allergic reactions. Arch Ophthalmol. 1995;113:293-296.

39. Barnebey HS, Robin AL, Zimmerman TJ, et al. The efficacy of brimonidine in decreasing elevations in intraocular pressure after laser trabeculoplasty. Ophthalmology. 1993;100(7):1083-1088.

40. Toris CB, Gleason ML, Camras CB, Yablonski ME. Effects of brimonidine on aqueous humor dynamics in human eyes. Arch Ophthalmol. 1995;113(12):1514-1517.

41. Toris CB, Camras CB, Yablonski ME. Acute versus chronic effects of brimonidine on aqueous humor dynamics in ocular hypertensive patients. Am J Ophthalmol. 1999;128:8-14.

42. Motolko MA. Comparison of allergy rates in glaucoma patients receiving brimonidine $0.2 \%$ monotherapy versus fixed-combination brimonidine 0.2\%-timolol 0.5\% therapy. Curr Med Res Opin. 2008;24(9): 2663-2667.

43. Osborne SA, Montgomery DM, Morris D, McKay IC. Alphagan allergy may increase the propensity for multiple eye-drop allergy. Eye (Lond). 2005; 19:129-137.

44. Alvarado JA, Murphy CG, Franse-Carman L, Chen J, Underwood JL. Effect of beta-adrenergic agonists on paracellular width and fluid flow across outflow pathway cells. Invest Ophthalmol Vis Sci. 1998; 39(10):1813-1822.

45. Schuman JS, Katz GJ, Lewis RA, et al. Efficacy and safety of a fixed combination of travoprost $0.004 \%$ /timolol $0.5 \%$ ophthalmic solution once daily for open-angle glaucoma or ocular hypertension. Am J Ophthalmol. 2005;140(2):242-250.

46. Hughes BA, Bacharach J, Craven ER, et al. A three-month, multicenter, double-masked study of the safety and efficacy of travoprost $0.004 \%$ / timolol $0.5 \%$ ophthalmic solution compared to travoprost $0.004 \%$ ophthalmic solution and timolol $0.5 \%$ dosed concomitantly in subjects with open angle glaucoma or ocular hypertension. J Glaucoma. 2005;14(5):392-399.

47. Hommer A, Ganfort Investigators Group I. A double-masked, randomized, parallel comparison of a fixed combination of bimatoprost $0.03 \%$ / timolol $0.5 \%$ with non-fixed combination use in patients with glaucoma or ocular hypertension. Eur J Ophthalmol. 2007;17(1):53-62.
Clinical Ophthalmology

\section{Publish your work in this journal}

Clinical Ophthalmology is an international, peer-reviewed journal covering all subspecialties within ophthalmology. Key topics include: Optometry; Visual science; Pharmacology and drug therapy in eye diseases; Basic Sciences; Primary and Secondary eye care; Patient Safety and Quality of Care Improvements. This journal is indexed on Submit your manuscript here: http://www.dovepress.com/clinical-ophthalmology-journal

\section{Dovepress}

PubMed Central and CAS, and is the official journal of The Society of Clinical Ophthalmology (SCO). The manuscript management system is completely online and includes a very quick and fair peer-review system, which is all easy to use. Visit http://www.dovepress.com/ testimonials.php to read real quotes from published authors. 